\title{
The frequency of reduction loss after arthroscopic fixation of acute acromioclavicular dislocations using a double-button device, and its effect on clinical and radiological results
}

\section{Engin Çarkçı}

Istanbul Egitim ve Arastirma Hastanesi

Ayşe E Polat ( $\square$ ayseesinuygur@gmail.com )

Dr. Akcicek State Hospital https://orcid.org/0000-0001-9592-5193

Tahsin Gürpınar

Istanbul Egitim ve Arastirma Hastanesi

\section{Research article}

Keywords: Acromioclavicular joint, Dislocation, Endobutton, Arthroscopy, Coracoclavicular distance

Posted Date: January 2nd, 2020

DOl: https://doi.org/10.21203/rs.2.19921/v1

License: (9) (i) This work is licensed under a Creative Commons Attribution 4.0 International License.

Read Full License

Version of Record: A version of this preprint was published at Journal of Orthopaedic Surgery and Research on April 8th, 2020. See the published version at https://doi.org/10.1186/s13018-020-01674-x. 


\section{Abstract}

Background The aim of this study was to investigate the effect of reduction loss of more than $3 \mathrm{~mm}$ on clinical and radiological results after at least 2 years of follow-up after arthroscopic fixation of acute acromioclavicular joint dislocations using a double-button device.

Methods Thirty-six patients who had acute ( $<3$ weeks old), type III or V Acromioclavicular (AC) joint dislocations underwent arthroscopic fixation of the AC joint using a double-button device. Clinical and radiological evaluations were performed at preoperative, postoperative first day, 3 months and last followup. When the coracoclavicular (CC) distances of patients at the last follow-up were compared to the early postop CC distances, those with a difference of $3 \mathrm{~mm}$ or less were grouped as group A and those with a difference of more than $3 \mathrm{~mm}$ were grouped as group B.

Results There was no statistically significant difference between the groups in terms of age, gender, follow-up time, time from injury to surgery, return to work, and distribution of Rockwood classification. Pre-operative CC distance was reduced from $18.7 \pm 3.5$ to $8.5 \pm 0.6$ in the early postoperative period. Anatomic reduction was achieved in all patients compared with the unaffected side (CC distance $8.6 \pm$ 0.7). However, the CC distance increased to $9.9 \pm 1.5$ at the third month follow-up and increased to $11 \pm$ 2.7 at the last follow-up. There were no significant Constant score differences between the groups in the preoperative and last follow-up periods $(p>0.05)$. At the last follow-up, the mean Acromioclavicular Joint Instability (ACJI) score of group A was $84.4 \pm 8$, whereas it was $68.3 \pm 8.3$ for group $B$, and the difference was statistically significant $(p<0.01)$. Furthermore, the subjective evaluation and aesthetic subjective satisfaction values of group $B$ were lower than group $A(p<0.01)$.

Conclusions Reduction loss of more than $3 \mathrm{~mm}$ was observed in $25 \%$ of patients after arthroscopic fixation of acute acromioclavicular dislocations using a double-button device. Although this loss did not create a statistically significant difference in Constant scores, AC joint-specific tests such as ACJl, subjective evaluation, and aesthetic subjective satisfaction values were significantly impaired.

\section{Background}

Acromioclavicular (AC) joint dislocation is not a common orthopaedic injury with the incidence of 1.8 per 10,000 per year [1]. Rockwood divided AC dislocations into six types and according to current recommendations; Types IV through VI are managed by surgical reconstruction and treatment of type III should be individualized based on the patient's demands, activity level, and response to conservative treatment. There are several methods used for fixation like K-wires, hook plate, Bosworth screw, WeaverDunn and resection of the lateral end of the clavicle, but there is no gold standard procedure [2-4]. Recently, arthroscopic techniques have been successfully proposed to treat AC joint dislocations [5-7]. However, despite continuous development in surgical management, current techniques are still associated with many significant complications including under-correction, loss of reduction, coracoid fractures, clavicle fractures, infection and adhesive capsulitis [8]. 
In order to solve complications such as reduction loss, techniques including opening of a second tunnel [9], supporting the existing tunnel with anchor to the coracoid [10] and using tendon graft [11] have been proposed by different authors. However, none of these techniques have been widely accepted. Furthermore, these additional procedures make the cases more complex and harder to manage.

We have been using an adjustable loop double button device (Smith Nephew) for arthroscopic fixation of acute AC joint disruption ( $<3$ weeks) without additional augmentation for the last 4 years in our hospital. Clinical and radiological outcomes of patients and the loss of reduction with this technique have not been widely studied in the literature. The aim of this study was to investigate the effect of reduction loss of more than $3 \mathrm{~mm}$ on clinical and radiological results after at least 2 years of follow-up after arthroscopic fixation of acute acromioclavicular joint dislocations using a double-button device.

\section{Methods}

The study protocol was approved by the institutional review board of our hospital (2019 No:2051) and we retrospectively reviewed the medical records of patients with AC joint dislocation who were treated arthroscopically in our institution between July 2015 and July 2017. Only acute cases ( $<3$ weeks old), type III or V AC joint dislocations who had a minimum 2-year follow-up with availability of all records were included in the study. Patients with other dislocation types, presence of acromial, coracoid or clavicular fracture, with associated rotator cuff, labral, glenohumeral or biceps tendon injury diagnosed during the arthroscopic procedure were excluded. A total of 41 patients met the inclusion criteria, but 5 patients were lost at the last follow-up. Finally, the remaining 36 patients were enrolled in this study. The anteroposterior radiographic views of the bilateral AC joints were taken of all patients in order to diagnose and evaluate each AC joint dislocation before operating. All operations were performed by the same senior surgeon (T.G.) with the technique described below. If there was a difference of more than $3 \mathrm{~mm}$ difference between the coracoclavicular (CC) distance at last follow-up compared to early postop, this was considered as reduction loss. When the patients' CC distances at last follow up were compared to the early postop CC distance, those with a difference of $3 \mathrm{~mm}$ or less were grouped as group $A$ and those with a difference of more than $3 \mathrm{~mm}$ were grouped as group $B$.

\section{Surgical Technique}

Patients were placed in the beach chair position under general anaesthesia. After establishment of the standard posterior portal, an anterior portal through the rotator interval using an outside-in technique was opened. The glenohumeral joint was first evaluated with a $30^{\circ}$ scope and the rotator interval was opened using a radiofrequency device. After that, the scope was changed to $70^{\circ}$ and the base of the coracoid was exposed using the radiofrequency device. A $2-3 \mathrm{~cm}$ incision was made over the clavicle $3-4 \mathrm{~cm}$ far from the AC joint and the centre of the clavicle was identified. The drill guide was inserted through the anterior portal, and the guide tip was positioned under the coracoid base. A 2.4-mm guide pin was inserted from the clavicle to the coracoid. A 4-mm cannulated drill was then passed over the pin and through the coracoid. The pin was then removed, and the drill was left in situ. A Number 3 Prolene suture was passed 
through the drill and taken out through the anterosuperior portal using an arthroscopic grasper, leaving the suture loop superiorly. The drill was then removed and the Prolene was used to pass the ethibond attached to one side of the double loop endobutton system. The traction was applied from the anterior portal and a grasper was also used to pass the endobutton through the coracoid. Once the button passed under the coracoid, the trailing suture was used to flip it, locking it under the bone. The clavicle was then reduced by the surgical assistant. The sutures were tied over the top of the superior button. The wounds were then closed in layers.

A shoulder sling was worn for 4 weeks. Passive range of motion exercise began 2 weeks after the operation. Strengthening exercises began at 8 weeks, and the patients were allowed to perform heavy weight lifting at 3 months after the operation. Contact sports were not permitted until 6 months after the operation.

\section{Clinical Evaluation}

Patients' demographics, trauma mechanism, associated injuries and time from injury to surgery were questioned and noted preoperatively. Clinical follow-up was performed preoperatively and at last followup. Radiological follow-up was performed preoperatively, early postoperatively, at 3 months and at the last follow-up. Patients were clinically evaluated using preoperative and postoperative Constant, Subjective evaluation and aesthetic subjective satisfaction at last follow-up. The patients were questioned to subjectively evaluate the injured shoulder as excellent, good, fair and poor. Furthermore, patients were asked to describe their aesthetic subjective satisfaction as highly satisfied, satisfied, poorly satisfied and unsatisfied. In addition, we used the Acromioclavicular Joint Instability Score (ACJI) [12] in order to evaluate the AC joint specifically, since Constant is not specific to AC joint. The ACJI evaluates 5 variables including pain, daily living activities, cosmesis, function and radiological evaluation.

Radiological evaluation included anteroposterior (AP), axillar, and Zanca views of each shoulder and bilateral stress radiographs. Alexander view radiographs were obtained in order to calculate the ACJI score at the last follow-up. Dislocations were graded according to the Rockwood classification. CC distance was calculated at preoperative, early postoperative, postoperative 3 months and postoperative last follow-up on X-rays as the perpendicular distance between the uppermost point of the superior cortex of the coracoid and the undersurface of the clavicle and then compared with the normal side. Mean values were recorded in millimetres for the vertical distance using a digital caliper in picture archiving and communication system by two different orthopaedic surgeons and averaged. $\Delta$ : side to side difference in $\%$ of a distance measure at last follow-up. The imaging studies were also examined for any loss of reduction in the $\mathrm{AC}$ joint, or other possible complications, such as fracture, hardware migration, or heterotopic ossification. Demographic characteristics, functional and radiological scores of patients between groups were compared.

Statistical Analysis: 
Mean, standard deviation, median lowest, highest, frequency and ratio values were used in descriptive statistics of the data. The Chi-square test was used for the analysis of qualitative independent data and the Fisher test was used when the chi-square test conditions were not met. The Mann-Whitney test was used to analyze quantitative independent data. SPSS 18.0 program was used in the analysis.

\section{Results}

The mean age was $30.6 \pm 7.51$ years (range, 20-52). 32 patients were male and 4 were female. The mean follow-up was $31.4 \pm 5.9$ months (range, 24-48). According to the Rockwood classification, there were 14 type III and 22 type $V$ dislocations. Mean time from injury to surgery was $6.8 \pm 3.8$ days (range, $2-14$ ). The mean time to return to work was $11.2 \pm 2.9$ weeks (range, 8-20). When trauma mechanisms are examined, 15 patients were injured while doing sports, 14 patients were injured after a traffic accident, 5 patients were injured after falling from height and 2 patients were injured during a fight. When the accompanying traumas were examined, 4 patients had thorax trauma, 2 patients had head trauma and 1 patient had lumbar fractures (Table 1).

There was an improvement in the mean Constant-Murley Shoulder Score from 27.8 \pm 7.9 (range, 18-46) pre-operatively to $92 \pm 4.6$ (range $82-100$ ) post-operatively, which was statistically significant $(P<0.05)$. The mean ACJI score was $80.4 \pm 10.6$ at the last follow-up. According to the subjective evaluation, $72.2 \%$ of the patients rated the result as excellent and $27.8 \%$ of the patients rated it as good. When aesthetic subjective satisfaction was questioned, $72.2 \%$ of the patients stated that they were highly satisfied, $19.5 \%$ were satisfied and $8.3 \%$ expressed low satisfaction. When the patients were examined radiologically, the pre-operative CC distance was reduced from $18.7 \pm 3.5$ to $8.5 \pm 0.6$ in the early postoperative period. Anatomic reduction was achieved in all patients compared with the unaffected side (CC distance $8.6 \pm$ 0.7). However, the CC distance increased to $9.9 \pm 1.5$ at the third month follow-up and increased to $11 \pm$ 2.7 at the last follow-up. The mean loss of reduction was $27.4 \% \pm 28.6 \%$ (range, $0-100$ ) compared to the unaffected side at the last follow-up (Table 2).

There was no statistically significant difference between the groups in terms of age, gender, follow-up time, time from injury to surgery, return to work, distribution of Rockwood classification. There were no significant Constant score differences between the groups in the preoperative and last follow-up periods ( $p>0.05$ ). At the last follow-up, the mean ACJI score of group A was $84.4 \pm 8$, whereas it was $68.3 \pm 8.3$ for group $B$, and the difference was statistically significant $(p<0.01)$. Furthermore, there was a significant difference between groups in terms of subjective evaluation and aesthetic subjective satisfaction ( $p$ $<0.01)$. There was no statistically significant difference between the CC distance of groups in the preoperative and early postoperative periods. On the other hand, it was found that CC distance was statistically lower in group A than in group B at 3 months and last follow-up control. When CC distances were compared to unaffected side at the last follow-up, 13.2\% \pm 10.6 (range, $0-33.3$ ) of reduction loss was observed in group $A$ and $70 \% \pm 2.2$ (range, 33.3-100) of reduction loss was observed in group $B$. This difference is statistically significant $(p<0.01)$ (Table 3 ). No complications including tunnel malposition or 
early implant failure leading to revision were observed. In addition, no fractures of the coracoid or the clavicle were encountered.

\section{Discussion}

There is no consensus regarding the ideal surgical technique for $\mathrm{AC}$ joint dislocation [4]. Different open and arthroscopic techniques have been proposed in the literature. Recently, clinical and biomechanical studies have shown that suture button fixations are effective for coracoclavicular reconstruction of the joint $[5,12,13]$. In this procedure, the CC ligaments are expected to heal since the AC joint is kept reduced and the $\mathrm{AC}$ and $\mathrm{CC}$ ligament remnants are brought into contact. In a systemic meta-analysis, loop fixation devices were found to have higher shoulder function scores and lower postoperative pain [14]. Another study comparing the results of loop button fixation and Bosworth screw fixation showed that more treatment satisfaction is achieved with loop fixation [15]. Our study showed that arthroscopic fixation of acute acromioclavicular joint disruptions (type III and V) by using a double button device achieves satisfactory outcomes. Our findings are consistent with other authors reporting satisfactory outcomes using similar techniques and device.

Biomechanical studies have shown that button systems provide excellent supero-inferior stability with load to failure higher than native ligament $[16,17]$. However, horizontal instability in AC dislocations is increasingly being treated with $\mathrm{AC}$ repair, with an additional acromioclavicular sling [18]. AC repair was not performed in any of the patients in this study group since it requires wider dissection and longer surgery, has higher morbidity and the additional stability is questionable. In a cadaver study, Weiser et al. did not observe any additional stability with direct AC repair [19].

The patients in our study were operated by using a single tunnel to avoid the risk of coracoid fracture. In a biomechanical study by Beitzel et al. [13], there was no difference in stability between the single and double device; nevertheless the coracoid fracture incidence was much higher with the double device. Likewise, a recent study demonstrated that single tunnel reconstruction demonstrates similar biomechanical properties to the intact state and double tunnel reconstruction [9].

Coracoid fractures have been reported as a potential complication in the literature [20]. We did not have any such complications. We believe that appropriate visualization of the inferior surface of coracoid process and drilling with a $4 \mathrm{~mm}$ drill close to the base of the coracoid is essential. In a cadaveric study, Rylander et al. [21] showed that a 4-mm tunnel technique is significantly stronger than a 6-mm tunnel technique when using a transcoracoid reconstruction technique. In addition, tunnel placement is also a significant factor to avoid coracoid fractures and failure of fixation. In a recent study, higher peak load to failure was found when a centre-centre or medial-centre tunnel orientation was performed during drilling [22].

Recently, some authors have suggested CC ligament reconstruction by using tendon grafting [23]. However, in another study, $47 \%$ reduction loss and $20 \%$ complications were seen after CC ligament reconstruction with an autologous tendon graft, which adversely affected the results [11]. Many previous 
open procedures treating the AC joint dislocation without tendon reconstruction, such as hook plate fixation, K-wire, and Bosworth type screw fixation have shown good results after the implants were removed. Therefore, we believe it is viable to do the $\mathrm{CC}$ ligament reconstruction without ligamentous augmentation.

The most commonly reported complication after AC joint reconstruction is loss of reduction. In this study, 9 of 36 patients had a reduction loss greater than $3 \mathrm{~mm}$ CC distance compared with the unaffected side.

There are some possibilities for the reduction loss. In patients operated with the Single Flip Button Device Technique, reduction loss has been shown to be caused by a longer duration between injury and treatment of more than 5 days and poor quality of initial reduction (more than $2 \mathrm{~mm}$ CC distance difference in early postop radiological examination) [24]. In our study, no statistically significant difference was observed between groups with and without reduction loss in terms of time from injury to treatment. In addition, early radiological examination revealed a CC difference of less than $2 \mathrm{~mm}$ in all patients. Our adjustable loop system only mimics one component of the CC ligament and the AC ligament was not also reconstructed. Undue forces on the AC joint may cause instability and damage the healing process of the CC ligaments. In addition, excessive force on the bone metal button interface may result in bone erosion, clavicular tunnel widening and cause loss of reduction [25]. Another reason could be loosening of the adjustable loop system. Zhang et al. [26] showed $25 \%$ fixation failure rate within 3-6 months after CC fixation using a similar suspensory fixation device. In different series, reduction loss varies; however, good or excellent outcomes are reported regardless of fixation loss. Murena et al. [27] reported outcomes of 16 patients with AC dislocation treated by the double flip button technique. Although $25 \%$ of the patients had a reduction loss, the average constant score was 97.

De Carli et al. compared the functional results of patients with double button fixation and conservative treatment of 3rd degree AC joint dislocations. According to this study, although there was no difference in terms of non-AC joint-specific objective scores in the surgical group, a statistically significant difference was found in the AC joint-specific objective measurements, subjective evaluation of patients and aesthetic satisfaction [28]. In our study, although there was no difference in non-AC joint-specific objective scores in the group without loss of reduction, a statistically significant difference was found in AC joint specific objective scores, subjective assessment and aesthetic satisfaction. Therefore, the authors believe that reduction maintaining is crucial for excellent functional and aesthetic results after fixation of the $A C$ joint with a double button device.

There are some limitations of this study. First, the number of patients was small. Second, our follow up time was not sufficient to make conclusion about the incidence of post-traumatic arthritis; however, we were able to show early results and complications since most of the reduction loss occurs in a short time.

\section{Conclusion}

Reduction loss of more than $3 \mathrm{~mm}$ was observed in $25 \%$ of patients after arthroscopic fixation of acute acromioclavicular dislocations using a double-button device. Although this loss did not create a 
statistically significant difference in Constant scores, AC joint-specific tests such as ACJI, Subjective evaluation, and aesthetic subjective satisfaction values were significantly impaired.

\section{Abbreviations}

AC

Acromioclavicular

CC

Coracoclavicular

ACJI

Acromioclavicular Joint Instability

\section{Declarations}

\section{Acknowledgements}

We like to thank the patients who participate in this study.

\section{Funding}

None; This research did not receive any specific grant from funding agencies in the public, commercial, or not-for-profit sectors.

\section{Availability of data and materials}

The data of this study were real and were performed in SPSS (Version 22.0). The statistical results of the data are presented in the main paper. All of the data are available in contact with the correspondence author.

\section{Author Contributions}

EÇ and AEP contributed to the study design, data analysis, assisted with operation and were a major contributor in writing the manuscript. EÇ contributed to the data collection, organized the operation and manuscript preparation. EC and TG performed surgeries, contributed to the data analysis and revised the manuscript. All authors read and approved the final manuscript.

\section{Ethics approval and consent to participate}

Informed consent was obtained from all the individual participants included in the study. The study was conducted according to the Helsinki Declaration (Ethical Principles for Medical Research Involving Human Subjects) and was approved by the ethics committee of Istanbul Training and Research Hospital. 
All consents to publish from the patients who took part in this study were obtained.

\section{Competing interests}

The authors declare that they have competing interest.

\section{References}

1. Chillemi C, Franceschini V, Dei Giudici L, Alibardi A, Salate Santone F, Ramos Alday LJ, Osimani M. Epidemiology of isolated acromioclavicular joint dislocation. Emerg Med Int. 2013;2013:171609.

2. Metzlaff S, Rosslenbroich S, Forkel PH, Schliemann B, Arshad H, et al. Surgical treatment of acute acromioclavicular joint dislocations: hook plate versus minimally invasive reconstruction. Knee Surg Sports Traumatol Arthrosc. 2016;24:1972-8.

3. Cetinkaya E, Arıkan Y, Beng K, Mutlu H, Yalçınkaya M, Üzümcügil O. Bosworth and modified Phemister techniques revisited. A comparison of intraarticular vs extraarticular fixation methods in the treatment of acute Rockwood type III acromioclavicular dislocations. Acta Orthop Traumatol Turc. 2017;51:455-8.

4. Beitzel K, Cote MP, Apostolakos J, Solovyova O, Judson CH, et al. Current concepts in the treatment of acromioclavicular joint dislocations. Arthroscopy. 2013;28:387-97.

5. Spoliti M, De Cupis M, Via AG, Oliva F. All arthroscopic stabilization of acute acromioclavicular joint dislocation with fiberwire and endobutton system. Muscles Ligaments Tendons J. 2015;4:398-403.

6. Chaudhary D, Jain V, Joshi D, Jain JK, Goyal A, Mehta N. Arthroscopic fixation for acute acromioclavicular joint disruption using the TightRope device. J Orthop Surg. 2015;23:309-14.

7. Hann C, Kraus N, Minkus M, Maziak N, Scheibel M. Combined arthroscopically assisted coraco- and acromioclavicular stabilization of acute high-grade acromioclavicular joint separations. Knee Surg Sports Traumatol Arthrosc. 2018;26:212-20.

8. Milewski MD, Tompkins M, Giugale JM, Carson EW, Miller MD, Diduch DR. Complications related to anatomic reconstruction of the coracoclavicular ligaments. Am J Sports Med. 2012;40:1628-34.

9. Banffy MB, Uquillas C, Neumann JA, ElAttrache NS. Biomechanical Evaluation of a Single- Versus Double-Tunnel Coracoclavicular Ligament Reconstruction With Acromioclavicular Stabilization for Acromioclavicular Joint Injuries. Am J Sports Med. 2018;46:1070-6.

10. Choi S, Lee TJ, Kim MK, Park JE, Kang H. Midterm results of coracoclavicular stabilization with double augmentation for acute acromioclavicular dislocation. Springerplus 2016;5:1858.

11. Choi NH, Lim SM, Lee SY, Lim TK. Loss of reduction and complication of coracoclavicular ligament reconstruction with autogenous tendon graft in acute acromioclavicular dislocations. J Shoulder Elbow Surg. 2017;26:692-8.

12. Scheibel M, Dröschel S, Gerhardt C, Kraus N. Arthroscopically assisted stabilization of acute highgrade acromioclavicular joint separations. Am J Sports Med. 2011;39:1507-16. 
13. Beitzel K, Obopilwe E, Chowaniec DM, Niver GE, Nowak MD, et al. Biomechanical comparison of arthroscopic repairs for acromioclavicular joint instability: suture button systems without biological augmentation. Am J Sports Med. 2011;39:2218-25.

14. Arirachakaran A, Boonard M, Piyapittayanun P, Kanchanatawan W, et al. Post-operative outcomes and complications of suspensory loop fixation device versus hook plate in acute unstable acromioclavicular joint dislocation: a systematic review and meta-analysis. J Orthop Traumatol. 2017;18:293-304.

15. Darabos N, Vlahovic I, Gusic N, Darabos A, Bakota B, Miklic D. Is AC TightRope fixation better than Bosworth screw fixation for minimally invasive operative treatment of Rockwood III AC joint injury? Injury. 2015;46:S113-118.

16. Nüchtern JV, Sellenschloh K, Bishop N, Jauch S, Briem D, et al. Biomechanical evaluation of 3 stabilization methods on acromioclavicular joint dislocations. Am J Sports Med. 2013;41:1387-94.

17. Lädermann A, Gueorguiev B, Stimec B, Fasel J, Rothstock S, Hoffmeyer P. Acromioclavicular joint reconstruction: a comparative biomechanical study of three techniques. J Shoulder Elbow Surg. 2013;22:171-8.

18. Saier T, Venjakob AJ, Minzlaff P, Föhr P, Lindell F, Imhoff AB, et al. Value of additional acromioclavicular cerclage for horizontal stability in complete acromioclavicular separation: a biomechanical study. Knee Surg Sports Traumatol Arthrosc. 2015;23:1498-505.

19. Weiser L, Nüchtern JV, Sellenschloh K, Püschel K, Morlock MM, et al. Acromioclavicular joint dislocations: coracoclavicular reconstruction with and without additional direct acromioclavicular repair. Knee Surg Sports Traumatol Arthrosc. 2017;25:2025-31.

20. Gerhardt DC, VanDerWerf JD, Rylander LS, McCarty EC. Postoperative coracoid fracture after transcoracoid acromioclavicular joint reconstruction. J Shoulder Elbow Surg. 2011;20:e6-10.

21. Rylander LS, Baldini T, Mitchell JJ, Messina M, Justl Ellis IA, McCarty EC. Coracoclavicular ligament reconstruction: coracoid tunnel diameter correlates with failure risk. 2014;37:e531-5.

22. Ferreira JV, Chowaniec D, Obopilwe E, Nowak MD, Arciero RA, Mazzocca AD. Biomechanical evaluation of effect of coracoid tunnel placement on load to failure of fixation during repair of acromioclavicular joint dislocations. 2012;28:1230-6.

23. Wang G, Xie R, Mao T, Xing S. Treatment of AC dislocation by reconstructing CC and AC ligaments with allogenic tendons compared with hook plates. J Orthop Surg Res. 2018;13:175.

24. Lee YB, Kim J, Lee HW, Kim BS, Yoon WY, Yoo YS. Arthroscopically assisted coracoclavicular fixation using a single flip button device technique: What are the main factors affecting the maintenance of reduction? Biomed Res Int. 2017;2017:4859262.

25. Thangaraju S, Cepni S, Magosch P, Tauber M, Habermeyer P, Martetschlager F. Arthroscopically assisted acromioclavicular joint stabilization leads to significant clavicular tunnel widening in the early post-operative period. Knee Surg Sports Traumatol Arthrosc. 2019;Epub ahead of print. doi:10.1007/s00167-019-05662-5. 
26. Zhang LF, Yin B, Hou S, Han B, Huang DF. Arthroscopic fixation of acute acromioclavicular joint disruption with TightRope ${ }^{\mathrm{Tm}}$ : Outcome and complications after minimum 2 (2-5) years follow-up. J Orthop Surg. 2017;25:2309499016684493.

27. Murena L, Vulcano E, Ratti C, Cecconello L, Rolla PR, Surace MF. Arthroscopic treatment of acute acromioclavicular joint dislocation with double flip button. Knee Surg Sports Traumatol Arthrosc. 2009;17:1511-5.

28. DeCarli A, Lanzetti RM, Ciompi A, Lupariello D, Rota P, Ferretti A. Acromioclavicular third degree dislocation: surgical treatment in acute cases. J Orthop Surg Res. 2015;10:13.

\section{Tables}

Table 1: Demographic characteristics of patients

\begin{tabular}{|c|c|c|c|c|c|}
\hline \multirow{2}{*}{$\overline{\text { Age }}$} & & \multirow{2}{*}{$\frac{\text { Min }- \text { Max }}{20-52}$} & \multirow{2}{*}{$\frac{\text { Median }}{29.00}$} & \multicolumn{2}{|c|}{ Mean \pm sd / n - \% } \\
\hline & & & & & \pm 7.51 \\
\hline \multirow[t]{2}{*}{ Sex } & Female & & & 4 & $11.1 \%$ \\
\hline & Male & & & 32 & $88.9 \%$ \\
\hline Follow Up Time (month) & & $24-48$ & 30.00 & & \pm 5.89 \\
\hline \multirow[t]{4}{*}{ Trauma Mechanism } & Traffic Accident & & & 14 & $38.9 \%$ \\
\hline & Sports & & & 15 & $41.7 \%$ \\
\hline & Fall from aahaHeight & & & 5 & $13.9 \%$ \\
\hline & Fight & & & 2 & $5.5 \%$ \\
\hline \multirow[t]{3}{*}{ Associated Injuries } & Lumber fracture & & & 1 & $14.3 \%$ \\
\hline & Head trauma & & & 2 & $28.6 \%$ \\
\hline & Thorax trauma & & & 4 & $57.1 \%$ \\
\hline Time from injury to surgery & & $2-14$ & 5.00 & & \pm 3.85 \\
\hline \multicolumn{6}{|l|}{ sssssurgerySurgery (day) } \\
\hline \multirow[t]{2}{*}{ Rockwood Classification } & Type III & & & 14 & $38.9 \%$ \\
\hline & Type V & & & 22 & $61.1 \%$ \\
\hline Return to Work (month) & & $8-20$ & 10.00 & & \pm 2.88 \\
\hline
\end{tabular}

Table 2: Clinical and radiological results of patients 


$\begin{array}{lcc}\text { Min - Max } & \text { Median } & \text { Mean } \pm \mathrm{sd} / \\ \text { Max } & \mathrm{n}-\%\end{array}$

\section{Constant Score}

\begin{tabular}{|c|c|c|c|c|c|}
\hline Preop & & $18-46$ & 26.00 & \multicolumn{2}{|c|}{$27.78 \pm 7.93$} \\
\hline Last Follow up & & $82-100$ & 92.00 & \multicolumn{2}{|c|}{$92.03 \pm 4.62$} \\
\hline \multirow[t]{2}{*}{ Last Follow up ACJI Score } & & $60-95$ & 83.50 & \multicolumn{2}{|c|}{$80.39 \pm$} \\
\hline & & & & \multicolumn{2}{|c|}{10.62} \\
\hline \multirow[t]{2}{*}{ Subjective Evaluation } & Good & & & 10 & $27.8 \%$ \\
\hline & Excellent & & & 26 & $72.2 \%$ \\
\hline \multirow[t]{4}{*}{ Aesthetic Subjective Satisfaction } & Poorly & & & 3 & $8.3 \%$ \\
\hline & satisfied & & & & \\
\hline & Satisfied & & & 7 & $19.5 \%$ \\
\hline & Highly satisfied & & & 26 & $72.2 \%$ \\
\hline \multicolumn{6}{|l|}{ CC Distance $(\mathrm{mm})$} \\
\hline Unaffected Side & & $8-10$ & 9.00 & \multicolumn{2}{|c|}{$8.64 \pm 0.68$} \\
\hline Preop & & $13-24$ & 19.00 & \multicolumn{2}{|c|}{$18.72 \pm 3.53$} \\
\hline Early Post-op & & $8-10$ & 8.00 & \multicolumn{2}{|c|}{$8.47 \pm 0.61$} \\
\hline 3 Month & & $8-14$ & 9.00 & \multicolumn{2}{|c|}{$9.89 \pm 1.47$} \\
\hline Last Follow up & & $8-17$ & 10.00 & \multicolumn{2}{|c|}{$11.03 \pm 2.71$} \\
\hline Compare Unaffected Side at Last & & $0-100$ & 21.10 & \multicolumn{2}{|c|}{$27.43 \pm$} \\
\hline Follow up (\%) & & & & \multicolumn{2}{|c|}{28.55} \\
\hline
\end{tabular}

Table 3: Comparison of demographic, clinical and radiological outcomes between groups 


\begin{tabular}{|c|c|c|c|c|c|c|}
\hline & & \multicolumn{2}{|c|}{ Group A (n:27) } & \multicolumn{2}{|c|}{ Group B (n:9) } & \multirow[t]{2}{*}{$\mathrm{p}$} \\
\hline & & $\begin{array}{c}\text { Mean } \pm \text { sd } \\
/ \mathrm{n}-\%\end{array}$ & Median & $\begin{array}{c}\text { Mean } \pm \\
\text { sd / n - \% }\end{array}$ & Median & \\
\hline \multirow{2}{*}{\multicolumn{2}{|c|}{ Age }} & $29.89 \pm$ & 27.00 & $32.56 \pm$ & 33.00 & 0.133 \\
\hline & & 8.13 & & 5.13 & & $\mathrm{~m}$ \\
\hline \multirow[t]{2}{*}{ Sex } & Female & 3 & $11.1 \%$ & 1 & $11.1 \%$ & 0.999 \\
\hline & Male & 24 & $88.9 \%$ & 8 & $88.9 \%$ & $\mathrm{f}$ \\
\hline \multirow{2}{*}{\multicolumn{2}{|c|}{ Follow Up Time }} & $32.11 \pm$ & 30.00 & $29.33 \pm$ & 30.00 & 0.442 \\
\hline & & 6.49 & & 2.92 & & $\mathrm{~m}$ \\
\hline \multicolumn{2}{|c|}{ Time From Injury to } & $6.70 \pm 3.89$ & 5.00 & $7.00 \pm$ & 7.00 & 0.825 \\
\hline \multicolumn{2}{|l|}{ Surgery } & & & 3.94 & & $\mathrm{~m}$ \\
\hline \multirow{2}{*}{\multicolumn{2}{|c|}{ Return to Work }} & $10.59 \pm$ & 10.00 & $12.89 \pm$ & 12.00 & 0.068 \\
\hline & & 2.41 & & 3.62 & & $\mathrm{~m}$ \\
\hline Rockwood & Type III & 12 & $44.4 \%$ & 2 & $22.2 \%$ & 0.432 \\
\hline Classification & Type V & 15 & $55.6 \%$ & 7 & $77.8 \%$ & $\mathrm{f}$ \\
\hline \multicolumn{7}{|l|}{ Constant } \\
\hline \multirow{2}{*}{\multicolumn{2}{|c|}{ Preop }} & $28.48 \pm$ & 27.00 & $25.67 \pm$ & 22.00 & 0.226 \\
\hline & & 7.99 & & 7.81 & & $\mathrm{~m}$ \\
\hline \multirow{2}{*}{\multicolumn{2}{|c|}{ Last Follow up }} & $92.48 \pm$ & 92.00 & $90.67 \pm$ & 92.00 & 0.329 \\
\hline & & 4.78 & & 4.03 & & $\mathrm{~m}$ \\
\hline \multirow{2}{*}{\multicolumn{2}{|c|}{ Last Follow up ACJI Score }} & $84.41 \pm$ & 86.00 & $68.33 \pm$ & 64.00 & 0.000 \\
\hline & & 7.99 & & 8.28 & & $\mathrm{~m}$ \\
\hline
\end{tabular}

\section{Distance}

Unaffected Side

$8.52 \pm 0.64 \quad 8.00$

$9.00 \pm \quad 9.00$

0.067

0.71

$\mathrm{m}$

Preop

$\begin{array}{ccccc}18.48 \pm & 19.00 & 19.44 \pm & 20.00 & 0.508 \\ 3.69 & & 3.09 & & \mathrm{~m}\end{array}$

Early Post-op

$8.44 \pm 0.64 \quad 8.00$

$8.56 \pm \quad 9.00$

0.462 
3 Month

$$
9.22 \pm 0.80 \quad 9.00
$$

$11.89 \pm \quad 12.00$

0.000

Last Follow up

$$
9.63 \pm 1.01 \quad 10.00
$$

$15.22 \pm$

15.00

0.000

1.56

m

\begin{tabular}{lcccccc}
\hline $\begin{array}{l}\text { Compare Unaffected Side at Last Follow } \\
\text { up (\%) }\end{array}$ & $\begin{array}{c}13.24 \pm \\
10.60\end{array}$ & 12.50 & $70.02 \pm$ & 75.00 & $\mathbf{0 . 0 0 0}$ \\
Subjective & & 4 & $14.8 \%$ & 6 & $66.7 \%$ & $\mathbf{0 . 0 0 6}$ \\
Evaluation & Good & 23 & $85.2 \%$ & 3 & $33.3 \%$ & $\mathrm{f}$ \\
\hline Aesthetic Subjective & Poorly Satisfied & 0 & $0.0 \%$ & 3 & $33.3 \%$ & $\mathbf{0 . 0 1 2}$ \\
Satisfaction & Satisfied + & 27 & $100.0 \%$ & 6 & $66.7 \%$ & $\mathrm{f}$ \\
& Highly Satisfied & & & & & \\
\hline
\end{tabular}

